\title{
The frequency of pharmacological pain relief in university neonatal intensive care units
}

\author{
Ana Claudia Y. Prestes, ${ }^{1}$ Ruth Guinsburg, ${ }^{2}$ Rita C. X. Balda, ${ }^{3}$ \\ Sergio T. M. Marba, ${ }^{4}$ Ligia M. S. S. Rugolo, ${ }^{5}$ Paulo R. Pachi, ${ }^{6}$ Maria Regina Bentlin ${ }^{7}$
}

\begin{abstract}
Objective: To evaluate the use of drugs to relieve the pain of invasive procedures newborn infants cared for at a university hospital NICU.

Methods: A prospective cohort study of all newborn infants hospitalized in four NICU during October 2001. The following data were collected: demographic data of the hospitalized newborn infants; clinical morbidity; number of potentially painful procedures and frequency of analgesic administration. Factors associated with the use of analgesia in this cohort of patients were studied by multiple linear regression using SPSS 8.0.

Results: Ninety-one newborn infants were admitted to the NICU during the study period (1,025 patient-days). Only $25 \%$ of the 1,025 patient-days received systemic analgesia. No specific drugs were administered to relieve acute pain during any of the following painful events: arterial punctures, venous, capillary and lumbar punctures or intubations. For chest tube insertion, $100 \%$ of newborn infants received specific analgesia. For the insertion of central catheters $8 \%$ of the newborn infants received painkillers. Only nine of the 17 newborn infants that underwent surgical procedures received any analgesic dosage during the postoperative period. For $93 \%$ of patients under analgesia the drug of choice was fentanyl. The presence of mechanical ventilation increased the chance of newborn infants receiving painkillers by 6.9 times and the presence of chest tube increased this chance by five times.

Conclusion: It is necessary to train health professionals in order to bridge the gap between scientific knowledge regarding newborn infant pain and clinical practice.
\end{abstract}

J Pediatr (Rio J). 2005;81(5):405-10: Pain, acute pain, neonatal intensive care unit, newborn infant, analgesia.

1. MSc. Neonatologist, Universidade Federal de São Paulo - Escola Paulista de Medicina (UNIFESP/EPM), São Paulo, SP, Brazil.

2. PhD. Professor, UNIFESP/EPM, São Paulo, SP, Brazil.

3. PhD. Neonatologist, UNIFESP/EPM, São Paulo, SP, Brazil.

4. PhD. Professor, Faculdade de Ciências Médicas, Universidade Estadual de Campinas (UNICAMP), Campinas, SP, Brazil.

5. PhD. Professor, Medicine School, Universidade Estadual Paulista Júlio de Mesquita Filho (UNESP), São Paulo, SP, Brazil.

6. PhD. Assistant professor, Faculdade de Ciências Médicas da Santa Casa de São Paulo.

7. PhD. Professor, Medicine School, UNESP, São Paulo, SP, Brazil.

Manuscript received Feb 10 2005, accepted for publication May 112005.

Suggested citation: Prestes AC, Guinsburg R, Balda RC, Marba ST, Rugolo LM, Pachi PR, et al. The frequency of pharmacological pain relief in university neonatal intensive care units405. J Pediatr (Rio J). 2005;81:405-10.

\section{Introduction}

Even though the relief of pain is one of the basic principles of medicine, in practice analgesia is frequently ignored when patients have difficulties verbalizing sensations and sentiments. Since 1970, numerous studies have demonstrated that undertreatment of pain is common, especially in children and newborn infants. ${ }^{1-4}$ The difficulty in recognizing and alleviating pain during the neonatal period is one of the greatest obstacles to its adequate treatment in intensive care units. The lack of knowledge regarding valid tools for pain evaluation, definitive criteria for indication of pharmacologic pain relief and possible side effects of this class of drugs in this age group contribute to this situation. 
Newborn infants receiving intensive care are subject to several potentially painful interventions. In 2003 Simons et al. ${ }^{5}$ observed 151 neonates for the first 14 days after admission to an ICU and found that each of them was subjected to an average of 14 painful procedures per day. Prestes ${ }^{4}$ assessed four neonatal units at university hospitals in São Paulo for 1 month in 2001 and found an average of 3 to 5 potentially painful procedures per infant per day.

In Brazil there has been little research regarding the use of analgesia in NICU and the medical teaching on the subject. Evaluation of theoretical and practical teaching of themes related to neonatal pain at leading centers is important to improve understanding of the real situation of treatment of neonatal pain and to propose improvements in the management of these sick patients. Against this background, the objectives of this study were to analyze the frequency that analgesics are employed to relieve pain triggered by invasive procedures on newborn infants admitted to university NICU and to investigate the profile of analgesic usage with these neonates, i.e. the drugs chosen, the criteria for their indication and the factors associated with systemic analgesic usage.

\section{Methods}

This observational, multicenter study deals with a prospective cohort of newborn infants admitted to four university NICU in São Paulo state, two in the capital and two in the provinces. The research project was approved by the Research Ethics Committee of each institution. There was no need for informed consent from family members since this was an exercise to collect population data from the neonates admitted to the units in question, but the confidentiality of the information gathered from each patient and each unit was guaranteed. The research took place from the 1 st to the 31 st of October in 2001, at the four participating centers. The study month was chosen at random and, in terms of the number of admissions, the number of patients ventilated and the number of surgical patients, it represented the average for that year, at each of the units with the exception of one which was being refurbished and had reduced capacity during 5 months in 2001.

The only inclusion criterion was admission to one of the four university neonatal units during the study month. Therefore all newborn infants admitted, for whatever period (hours or days) or motive, to one of the four units according to the definitions of intensive care used at each institution were selected. The power of the sample was not assessed since all patients admitted during the month selected were studied.

Based on these criteria, data was collected prospectively on the characteristics of the units studied and of their patients, of the potentially painful procedures performed and the use of analgesics. The person responsible for each neonatal intensive care unit filled out a questionnaire with information on the general characteristics of the unit and the existence of written guidelines on pain and analgesia during the neonatal period.
Data on the characteristics of newborn infants admitted to each unit were collected by one neonatologist at each institution, and a record card per day filled out per institution. Therefore, information was obtained on all patients in each study unit and on patient-days. The following variables were included for each infant: birth weight, daily weight, age in days, days since admission, gender, gestational age and clinical problems. Main diagnoses were recorded for each day's stay in the intensive care unit. Any painful procedure carried out, or attempts to perform them, were recorded on a bedside chart that was filled out by the doctors and nurses who cared for the patients. Data from these charts were collected daily by the local coordinator. The following data were analyzed in order to evaluate the use of analgesics on the newborn infants admitted to the intensive care units during the study period:

- Patient-days on analgesia: total sum of patients in each unit who received at least one dose of analgesic for each day of the study.

- Indication for analgesia: the indications described for drug prescription on medical records were evaluated.

- Analgesics: observations were made of which analgesic medications were used.

- Patient-days on analgesia: the total sum of newborn infants in each intensive care unit that were given at least one dose of analgesic for each day of the study.

- Number of arterial punctures, venous, capillary and lumbar punctures on analgesia each day of the month under analysis.

- Number of tracheal intubations, thoracic drains, and central catheter insertions (umbilical, percutaneous or phlebotomy) phlebotomy under analgesia for each day of the month under analysis.

- Postoperative period under analgesia: newborn infants that were receiving some type of analgesic up to three days since they had undergone a surgical operation were counted for each day of the study.

- Numbers of ventilation-days, chest-tube-days and catheter-days under analgesia.

It should be pointed out that although the doctors and nurses were aware of the study protocol, they did not know that data collection included variables on pain relief. Furthermore, none of the local researchers were doing clinical work during the study month and so did not make any of the decisions on analgesia.

Logistic regression was chosen for the investigation of factors associated with the use of analgesics at the university neonatal units studied. ${ }^{6}$ The dependent variable was the use of at least one dose of an opioid analgesic, systemically, during the study month. The independent variables were chosen according to relevant literature on the subject. ${ }^{7-10}$ The final model estimated the chance of analgesic use according to the odds ratio obtained for each variable that remained significant after the removal of all non-significant variables and evaluation of the beta remainder coefficient 
and the significance of the model. This analysis was performed using SPSS 8.0 with $p \leq 0.05$ defined as significant.

\section{Results}

In order to maintain data confidentiality, the four institutions were labeled $A, B, C$ and $D$ at random. The total numbers of available beds were 60 at neonatal unit $A, 37$ at $B, 44$ at $C$ and 59 at D. Units $A, B$ and $C$ had 12 to 15 intensive care beds and $D$, which was being refurbished, had just six. The mean monthly number of births at units $A, B, C$ and $D$ were $300,100,120$ and 270, respectively. All of them were referral centers for high-risk pregnancies and had medical and nursing students and residents in pediatrics and neonatology. With respect to the teaching of pain management and analgesia, just one institution reported having a formal theoretical program on the subject. However, all four institutions reported that they held clinical discussions on the subject during neonatal bedside rounds.

During the study month, 39 newborn infants were admitted to institution $A, 19$ to $B, 17$ to $C$ and 16 to $D$, totaling 91 patients. The characteristics of these patients are shown in Table 1 . The most prevalent diseases in the patients at all institutions were respiratory conditions (54\%) and infections (39.5\%). Malformations were also frequent among the newborn infants admitted to all units evaluated, varying in frequency from 12 to $26 \%$ of neonates in intensive care during the study month. Regarding mortality, $16(17.5 \%)$ of the 91 newborn infants died at the four institutions approached.

The 91 neonates admitted to the four institutions totaled 1,025 patient-days. Two hundred and fifty-seven of these patient-days (25\%) were under analgesia. Institution B used analgesics most (43\%), followed by $C(27.5 \%)$ and then by institutions $A$ and $D$, where $20 \%$ of the patient-days during the study month were under analgesia. Just 35 ( $28 \%$ ) of the 91 newborn infants admitted to the four institutions received at least one dose of analgesic. The written indications for analgesia were: mechanical ventilation in $15(44 \%)$, postoperative period $(20 \%)$, reports of pain in four $(11 \%)$, agitation in one $(3 \%)$ and thoracic drainage in four $(11 \%)$ patients.

Fentanyl was used on $93 \%$ of the 257 patient-days under analgesia. At institutions A, B and D, 95 to $98 \%$ of the patient-days on analgesia were given fentanyl. At institution C, fentanyl was administered to $82 \%$ of the 51 patient-days on analgesia, $13 \%$ received tramadol and $5 \%$ received sulfentanyl.

Even though mechanical ventilation was the most common indication for analgesia, less than half of the mechanically ventilated infants (44\%) were given analgesics, taking all four institutions together. Analgesics were used within 3 days of a surgical procedure most often at institution $B$ ( $75 \%$ of patient-days). This figure was around $44 \%$ at $A$ and $C$ and at $D$ no surgical procedures were carried out during the study period. Overall, just nine $(53 \%)$ of the 17 neonates in the first three days of the postoperative period were given at least one dose of analgesia. Newborn infants who underwent annular pancreas or duodenal atresia correction, which are two major operations, were not given any type of analgesic during the postoperative period. The numbers of other painful procedures performed together with concurrent analgesic use are shown in Table 2. Regarding

Table 1 - Demographic data of newborns included in the study according to institution

\begin{tabular}{|c|c|c|c|c|}
\hline & $\begin{array}{c}A \\
n=39\end{array}$ & $\begin{array}{c}B \\
n=19\end{array}$ & $\begin{array}{c}C \\
n=17\end{array}$ & $\begin{array}{c}D \\
n=16\end{array}$ \\
\hline \multicolumn{5}{|l|}{ Birth weight (g) } \\
\hline Median & 1,610 & 1,925 & 2,070 & 1,132 \\
\hline Variation & $(710-4,000)$ & $(680-4,090)$ & $(775-3,650)$ & $(590-3,305)$ \\
\hline \multicolumn{5}{|c|}{ Gestational age (weeks) } \\
\hline Median & 33 & 35 & 33 & 33 \\
\hline Variation & $(25-41)$ & $(27-40)$ & $(27-42)$ & $(26-39)$ \\
\hline \multicolumn{5}{|c|}{ Weight at enrollment (g) } \\
\hline Median & 1,610 & 2,400 & 2,100 & 1,215 \\
\hline Variação & $(710-4,020)$ & $(680-6,700)$ & $(750-3,650)$ & $(590-3,205)$ \\
\hline \multicolumn{5}{|l|}{$\mathbf{A D} *$} \\
\hline Median & 1 & 1 & 3 & 1 \\
\hline Variation & $(0-96)$ & $(1-218)$ & $(1-46)$ & $(1-74)$ \\
\hline \multicolumn{5}{|l|}{ Gender } \\
\hline n (\%) masculino & $18(46 \%)$ & $10(53 \%)$ & $9(53 \%)$ & $13(81 \%)$ \\
\hline
\end{tabular}

$\mathrm{AD}=$ age in days at enrollment. 
necrotizing enterocolitis, which is known to be painful, 11 ten neonates had necrotizing enterocolitis and eight $(80 \%)$ of them were not given any analgesics during the acute phase of the disease.

In order to investigate factors associated with the use of analgesics at the units studied, an initial logistic regression model was built including the following variables: institution, age in days, weight at enrollment in the study, gender, presence or absence of mechanical ventilation, chest tube, postoperative period, and references to pain on the medical record. Based on this initial model, eight successive models were built until the model that best explained the use of analgesics was obtained with a likelihood ratio of 92.98 and $p<0.01$. In this final model, the fact of a patient being on mechanical ventilation increased their chances of receiving at least one dose of analgesic by 6.4 times (95\% CI: $1.7-23.9 ; p=0.006)$, and the fact of having a chest tube in place increased the chance by five times (95\% CI: $0.9-$ 24.5; $p=0.064)$.

\section{Discussion}

The four institutions were chosen because they are university centers, places where the human resources who will care for critically ill newborn infants are trained. All of them preferred to teach pain management in the neonatal period at the bedside. This training, therefore depends on the individual opinion of each different doctor that teaches a given group of students. The adoption of a minimum curriculum to teach pain and pain management in the neonatal period to pediatricians and neonatologists is recommended.

In terms of analgesic practice, just $23 \%$ of the 1,025 patient-days were given at least one dose of analgesic. Simon et al. ${ }^{5}$ observed 1,375 ICU patient-days within the first 14 days of life, reporting that 15 to $32 \%$ of these received at least one dose of analgesic per day of the study. This result is also similar to descriptions by Anand et al., ${ }^{2}$ who evaluated 1,068 newborn infants in 109 intensive care units in North America for 1 week, noting that $27 \%$ received analgesics. These data confirm that prescription of analgesics to just a small portion of the neonates receiving intensive care is a common practice.

The question was then whether the profile of analgesic prescriptions would differ between the institutions analyzed. Note that unit B used analgesics most ( $43 \%$ of the patientdays) and that, at the other units, the level varied from 17 to $27 \%$ of neonate-days received pharmacologic pain relief. Kahn et al. ${ }^{12}$ also evaluated pain management in 1,422 premature infants at six North-American units in 1998 with marked differences among these units. Divergences could be linked to factors related to the characteristics of the neonates themselves or of the healthcare professionals working there. ${ }^{7,10,13-17}$

Fentanyl (93\%) was the most prescribed analgesic in this study, in a similar manner to what has been reported by Anand and Selanikio ${ }^{18}$ and Castro et al.. 8 In contrast, Stevens et al. ${ }^{19}$ found that morphine was given twice as often as fentanyl at Canadian neonatal units. The choice of opioid made by the university centers from São Paulo is understandable when one considers the decrease amount of hemodynamic side effects of fentanyl compared with morphine. ${ }^{20}$ With reference to the indications for analgesia, it was found that mechanical ventilation accounted for $44 \%$ of opioid prescriptions, followed by the fact that a newborn was in postoperative period $(20 \%)$. The presence of pain was a minor indication for analgesia in the present study. These findings show that available methods for evaluating pain in infants have not been incorporated into clinical practice at the institutions studied.

Having looked at the general pattern of analgesia usage, it is interesting to observe how the acute pain triggered by each painful procedure was being alleviated. None of the infants were given any kind of anesthesia for venous arterial or capillary punctures. It is understandable that topical anesthetics are not used since there are no practical, safe and efficient local medication options that offer relief from the pain caused by minor procedures to neonates. ${ }^{21}$ These

Table 2 - Number of painful procedures performed together with concurrent analgesic use, percentage of newborns who were given specific analgesia for the procedure and of those under systemic analgesia during the event due to other indication than the procedure itself

\begin{tabular}{lccc}
\hline Painful procedures & Number & $\begin{array}{c}\text { \% specific analgesia } \\
\text { for the procedure }\end{array}$ & $\begin{array}{c}\text { \% systemic analgesia } \\
\text { (other reasons) }\end{array}$ \\
\hline Arterial punctures & 921 & zero & $41 \%$ \\
Venous punctures & 1,045 & zero & $29 \%$ \\
Capillary punctures & 1,437 & zero & $27 \%$ \\
Lumbar punctures & 64 & zero & $39 \%$ \\
Insertion of central catheters & 73 & $8 \%$ & $37 \%$ \\
Chest tube insertion & 8 & $100 \%$ & $75 \%$ \\
Tracheal cannula insertion & 115 & zero & $28 \%$ \\
\hline
\end{tabular}


results are similar to others published in the scientific literature. 22,23

Local administration of lidocaine for lumbar punctures is recommended during the neonatal period. ${ }^{11,24}$ Sabrine and Sinha ${ }^{3}$ verified the regular use of analgesics for lumbar puncture in $9 \%$ of the English neonatal ICU. Porter and Anand 22 studied 140 lumbar punctures, and analgesia was given specifically for that procedure in just $4 \%$. In the present study $39 \%$ of punctures were performed under analgesia, but all these patients were already receiving analgesics for other reasons and no specific pain relief was prescribed for any puncture.

Some benefits of using analgesics with premature infants who are on mechanical ventilation include attenuation of physiological and behavioral responses to pain ${ }^{25}$ and a reduced incidence of death and/or intraventricular hemorrhage degrees III/IV and/or periventricular leukomalacia. ${ }^{5,26} \mathrm{~A}$ multicenter study, however, published in 2004 by Anand et al. ${ }^{27}$ on the preemptive use of morphine in premature infants on mechanical ventilation reported an increased frequency of severe ventricular hemorrhage among patients with gestational ages from 27 to 29 weeks. Overall, even though the literature indicates that pain and discomfort in neonates on assisted ventilation exists and also that pain is possibly associated with long-term consequences, only one third of the ventilated patient-days studied here were given some type of analgesic. This finding is paradoxical since the main indication for analgesia in the studied units was mechanical ventilation.

Chest tube insertion contrasted with the profile seen up to this point, with $100 \%$ being carried out under analgesia at all four institutions. Chest tube insertion appears to lead to uniform concern about the possible pain experienced by the newborn. On the other hand, just $8 \%$ of the tracheal tube insertions were performed under analgesia at all four institutions as a group. This is a low figure when one considers that tracheal intubation is an invasive and painful procedure and that, when performed on adults, it is almost never done without analgesia and/or sedation.

It was the undertreatment of pain of the neonates subjected to surgery that triggered all of the scientific community's interest in the theme. ${ }^{28}$ In the present study a large proportion of newborn infants continue to be given no pain relief medication after minor, medium and even major surgery. The difficulty of incorporating knowledge regarding the existence and the consequences of pain to newborns into practice must be emphasized.

Finally, in order to find out which factors might explain the use of analgesics at the units, a logistic regression analysis was performed in an attempt to investigate whether factors distinct to each unit, characteristics of the newborns (age postnatal, weight and sex) and/or specific procedures (mechanical ventilation, chest drainage, post-op) could explain the employment of analgesics on the newborn infants admitted to university intensive care units. Neither the institution, nor the characteristics of the newborn infants themselves were associated with analgesia use. Why, therefore, were analgesics prescribed? The results indicate that analgesics were prescribed for newborn infants on mechanical ventilation, especially if fitted with a chest tube. Analgesia is therefore being used on the most unstable set of newborn infants from the clinical point of view, those that need the most intense, prolonged and invasive ventilatory support.

In the face of these findings the conclusion that can be drawn is that the patients admitted to university neonatal intensive care units are subjected to many potentially painful procedures and that the use of analgesics is still infrequent. It is necessary to improve health professionals' training in order to reduce the gap between current knowledge that exists on pain management in the neonatal period and actual clinical practice.

\section{References}

1. Mather $\mathrm{L}$, Mackie J. The incidence of postoperative pain in children. Pain. 1983;15:271-82.

2. Anand KJ, Craig KD. New perspectives on the definition of pain. Pain. 1996;67:3-6.

3. Sabrine N, Sinha S. Pain in neonates. Lancet. 2000;355:932-3.

4. Prestes AC. Epidemiologia da dor aguda em unidades de terapia intensiva neonatal universitárias: freqüência da realização de procedimentos dolorosos e do emprego de analgésicos por via sistêmica [dissertação]. São Paulo (SP): Universidade Federal de São Paulo; 2004.

5. Simons $S H$, van Dijk $M$, van Lingen RA, Roofthooft $D$, Duivenvoorden $\mathrm{HJ}$, Jongeneel $\mathrm{N}$, et al. Routine morphine infusion in preterm newborns who received ventilatory support: a randomized controlled trial. J Am Med Assoc. 2003;290:2419-27.

6. Kleinbaum DG. Logistic regression: a self-learning text. New York: Springer; 1996.

7. Balda RC. Fatores que interferem na comunicação da dor entre o recém-nascido e o adulto que o observa: influência das características pessoais e profissionais do observador [tese]. São Paulo (SP): Universidade Federal de São Paulo; 2001.

8. Castro MC, Guinsburg R, Almeida MF, Peres CA, Yanaguibashi G, Kopelman BI. Perfil da indicação de analgésicos opióides em recém-nascidos em ventilação pulmonar mecânica. J Pediatr (Rio J). 2003;79:41-8.

9. Chermont AG, Guinsburg R, Balda RC, Kopelman BI. O que os pediatras conhecem sobre avaliação e tratamento da dor no recém-nascido? J Pediatr (Rio J). 2003;79:265-72.

10. Elias LS. Os pais e os profissionais de saúde concordam quanto à avaliação da possível dor sentida por recém-nascidos internados em unidade de terapia intensiva? [dissertação]. São Paulo (SP): Universidade Federal de São Paulo; 2003.

11. Anand KJ, International Evidence-Based Group for Neonatal Pain. Consensus statement for the prevention and management of pain in the newborn. Arch Pediatr Adolesc Med. 2001;155: 173-80.

12. Kahn DJ, Richardson DK, Gray JE, Bednarek F, Rubin LP, Shah $B$, et al. Variation among neonatal intensive care units in narcotic administration. Arch Pediatr Adolesc Med. 1998;152: 844-51.

13. Burokas L. Factors affecting nurses' decisions to medicate pediatric patients after surgery. Heart Lung. 1985;14:373-9.

14. Schechter NL. The undertreatment of pain in children. Pediatr Clin North Am. 1989;36:781-94.

15. Hadjistavropoulos HD, Craig KD, Grunau RE, Whitfield MF. Judging pain in infants: behavioral, contextual and developmental determinants. Pain. 1997;73:319-24.

16. Guinsburg R, Peres CA, Almeida MF, Balda RC, Berenguel RC, Tonelotto J, et al. Differences in pain expression between male and female newborn infants. Pain. 2000;85:127-33.

17. Chambers CT, Giesbrecht K, Craig KD, Bennett SM, Hunstman E. A comparison of faces scales for measurement of pediatric pain: children's and parent's ratings. Pain. 1999;83:25-35.

18. Anand KJS, Selanikio JD, SOPAIN study group. Routine analgesic practices in 109 neonatal intensive care units. Pediatr Res. 1996;39:192A. 
19. Stevens B, McGrath P, Gibbins S, Beyene J, Breau L, Camfield $C$, et al. Procedural pain in newborns at risk for neurologic impairment. Pain. 2003;105:27-35.

20. Shannon M, Berde CB. Pharmacologic management of pain in children and adolescents. Pediatr Clin North Am. 1989;36:885-71.

21. Zempsky TW, Schechter NL. What's new in the management of pain in children. Pediatr Rev. 2003;24:337-48.

22. Porter FL, Anand KJ. Epidemiology of pain in neonates. Res Clin Forums. 1998;20:9-17.

23. Bauchner H, May A, Coates E. Use of analgesic agents for invasive medical procedures in pediatric and neonatal intensive care units. J Pediatr. 1992;121:647-9.

24. Porter F, Miller JP, Marshall RE. Local anesthesia for painful medical procedures in sick newborns. Pediatr Res. 1987;21:374A.

25. Guinsburg R, Kopelman BI, Anand KJ, Almeida MF, Peres CA, Miyoshi MH. Physiological, hormonal and behavioral response to a single fentanyl dose in intubated and ventilated preterm neonates. J Pediatr. 1998;132:954-9.

26. Anand $\mathrm{KJ}$, Barton BA, McIntosh N, Lagercrantz $H$, Pelausa $E$, Young $T E$, et al. Analgesia and sedation in preterm neonates who require ventilatory support. Arch Pediatr Adolesc Med. 1999;153:331-8.
27. Anand KJ, Hall RW, Desai N, Shephard B, Bergqvist LL, Young $T E$, et al. Effects of morphine analgesia in ventilated preterm neonates: primary outcomes from the NEOPAIN randomized trial. Lancet. 2004;363:1673-82.

28. Anand KJ, Brown MJ, Bloom SR, Aynsley-Green A. Studies on the hormonal regulation of fuel metabolism in the human newborn infant undergoing anaesthesia and surgery. Horm Res. $1985 ; 22: 115-28$

Correspondence:

Ana Claudia Yoshikumi Prestes

Rua Conde de Irajá, 184/54

CEP 04119-010 - São Paulo, SP, Brazil

Tel.: +55 115579.1676

Fax: +55 115579.4982

E-mail: yoshikumiac@terra.com.br 